\title{
Three-Dimensional Finite Elemental Analysis of Bone Stress near an Implant Placed at the Border between Mandible and Fibular Graft in Mandibular Reconstruction
}

\author{
Yukawa Ken, Tachikawa Noriko, Kasugai Shohei \\ Oral Implantology and Regenerative Dental Medicine, Department of Masticatory Function Rehabilitation, \\ Tokyo Medical and Dental University, Tokyo, Japan \\ Email: yukairm@tmd.ac.jp
}

Received 11 October 2015; accepted 10 November 2015; published 13 November 2015

Copyright (C) 2015 by authors and Scientific Research Publishing Inc.

This work is licensed under the Creative Commons Attribution International License (CC BY). http://creativecommons.org/licenses/by/4.0/

(c) (i) D Den Access

\begin{abstract}
Purpose: The aim of the present study was to use finite elemental analysis (FEA) to evaluate bone stress near an implant placed at the border between the mandible and fibular graft in mandibular reconstruction. Materials and Methods: A fibular model (FM) and transplantation model (TM) were constructed for FEA. In TM, mandible was on the mesial side and the fibular graft was on the distal side. The implant was positioned at the center of both bone models. In TM, it was placed on the border between the mandible and fibular graft. A $10-\mathrm{mm}$ implant was used in the monocortical model and a 15-mm implant was used in the bicortical model. The loading force was set at $100 \mathrm{~N}$, the angle was set at $90^{\circ}$, and the loading position was set as center, mesial, or distal on the upper surface of the prosthesis. Von Mises equivalent stress values of the bone near the implant collar and apex at the middle line between buccal and lingual side were measured. Results: In all models, stress values were significantly lower with center loading than with distal loading and mesial loading. In center loading, the stress values were significantly lower in the bicortical model than in the monocortical model. There were no significant differences in stress values between FM and TM in all conditions. Conclusions: Bone stress was least with the center loading position, which was further decreased by bicortical fixation. There was no increase in mechanical stress associated with placing an implant at the border between the mandible and the fibular graft.
\end{abstract}

\section{Keywords}

Finite Elemental Analysis, Mandibular Reconstruction, Fibular Graft, Dental Implant, Stress Analysis 


\section{Introduction}

Finite elemental analysis (FEA) is used to calculate component displacement, strain, and stress under internal and external loads in 2-dimensional or 3-dimensional (3D) computer models in various fields, including medical applications. In particular, manufacturers of dental devices use FEA to test products used in dental implantation, including the implant body, healing abutment, impression abutment, and drill kit, which are standardized during the production process. However, prosthetic appliances intended for natural teeth are not standardized because of individual differences among patients. Therefore, FEA is better suited for implant assessment; consequently, many studies have reported the standardization of dental implants by FEA [1]-[10].

Cancer treatment includes the resection of healthy tissues to minimize the incidence of recurrence. However, in orthopedic surgery for cancer treatment, the lack of bone continuity results in poor cosmesis, functional failure, and, ultimately, decreased quality of life (QOL) [11]. Autogenous bone grafts have been used to bridge bone gaps, and reconstruction using autogenous bone grafts with implants has been reported to have a good prognosis [12] [13]. Autogenous bone grafting has been applied to reconstruct various bones, including the ilium, scapula, and fibula.

The primary stability of a dental implant is dependent on the rigidity and resistance offered by cortical bone. Iliac bone is primarily composed of cancellous bone, and iliac graft offers less stability for implant placement in mandibular reconstruction [14] [15]. The scapula has a sufficient proportion of cortical bone but it is relatively thin and plate like. Hence, scapula is insufficient as a donor site [16]. In addition, the surgical duration is prolonged with the use of scapular grafts for mandibular construction because surgery is anatomically complex [17]. The fibula also has sufficient cortical bone; however, it has a triangular cross-section, which is smaller than that of the mandible. If a fibular graft is placed in line with the inferior border of the mandible, a large gap will exist between the superior border of fibular graft and the opposing teeth is created. Meanwhile, if the fibular graft is placed in line with the superior border of the mandible, there will be an asymmetry in the facial appearance, resulting in poor cosmesis [18]. Surgeons often place the implant apex in the cortical bone at the inferior border of the mandible. This method is called bicortical fixation, which has been shown to have superior stability than monocoritcal fixation. The use of bicortical fixation with fibular grafts has been reported [19] [20]. However, other studies have reported an increased risk of bone fracture associated with bicortical fixation [21]. Various problems with bicortical fixation have been cited, although there are an insufficient number of cases to arrive at a consensus. Therefore, the efficacy of bicortical fixation for reconstruction continues to be debated.

Kourkouta et al. [21] reported that the optimal position of the implant was $2 \mathrm{~mm}$ from the tooth using FEA. Yokoyama et al. [22] reported that stress to the implant body and bone was increased by the use of mesial cantilever prostheses. In our clinic, we have performed a fibular graft transplantation procedure with implant fixation for mandibular reconstruction, and this reconstruction has lasted for 13 years without any problems. In this case, implant was placed at a distance of $2 \mathrm{~mm}$ from the tooth, following the recommendations of a previous report. The implant was positioned at the border between the mandible and the fibular graft, with the mandible forming the mesial border and the fibular graft forming the distal border. Cortical bone, which is important to achieve implant stability, varies among bones. For example, mandible has a cortical bone thickness of $2 \mathrm{~mm}$ [23] [24], whereas fibula has a cortical thickness of $3.5 \mathrm{~mm}$ [25]. Although there are many reports in the literature about fibular grafts being supported with implants [12] [13] [18] [20] [25], none of them have described the mechanical stress of bone near the implant placed at the border between the mandible and fibular graft.

This report had described both a fibular model (FM) and a transplantation model (TM), in which the implant was placed using bicortical or monocortical fixation at the center of the fibular graft or at the border between the mandible and the fibular graft, respectively. The aim of the present study was to use FEA to evaluate bone stress near the implant placed at the border between the mandible and fibular graft.

\section{Materials and Methods}

Autodesk Inventor Professional software (version 2013, Autodesk, Inc., Mill Valley, CA, USA) was used to create a digital 3D model to design, visualize, and simulate stress to the implant models Bone models consisted of 2 layers: a cortical layer and a cancellous layer (Figure 1). The height of all bone models was set at $15.0 \mathrm{~mm}$ (Figure 2). The height of fibular cortex was set at $3.5 \mathrm{~mm} \mathrm{[25]} \mathrm{and} \mathrm{that} \mathrm{of} \mathrm{mandibular} \mathrm{cortex} \mathrm{was} \mathrm{set} \mathrm{at} 2.0 \mathrm{~mm}$ [23] [24]. The remaining height of the cancellous bone was set at $8.0 \mathrm{~mm}$ for the fibular side and $11.0 \mathrm{~mm}$ for the mandibular side. In TM, the mandible formed the mesial border and the fibula formed the distal border. Two 


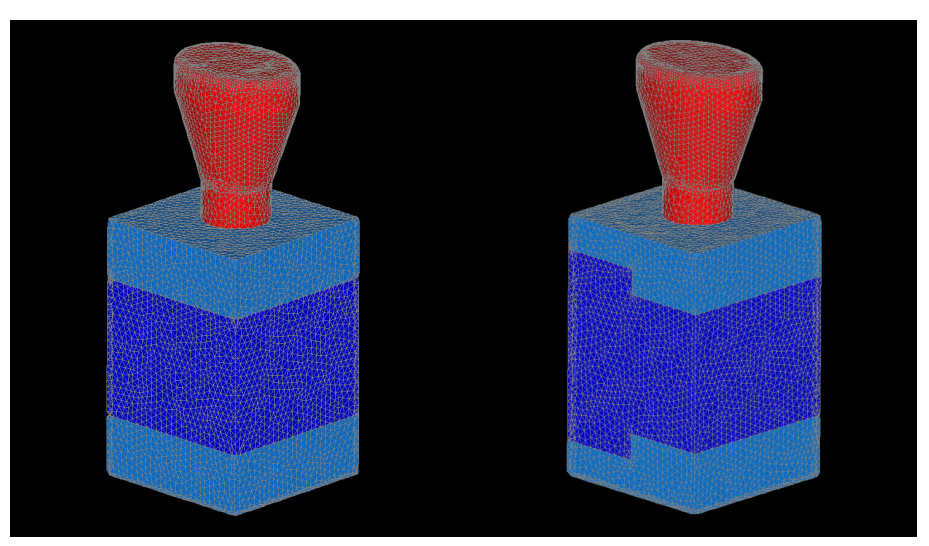

Figure 1. (Left) Fibular model with an implant. (Right) Transplantation model with an implant. The size of both models were width $10 \mathrm{~mm} \times$ depth $10 \mathrm{~mm} \times$ high $15 \mathrm{~mm}$.

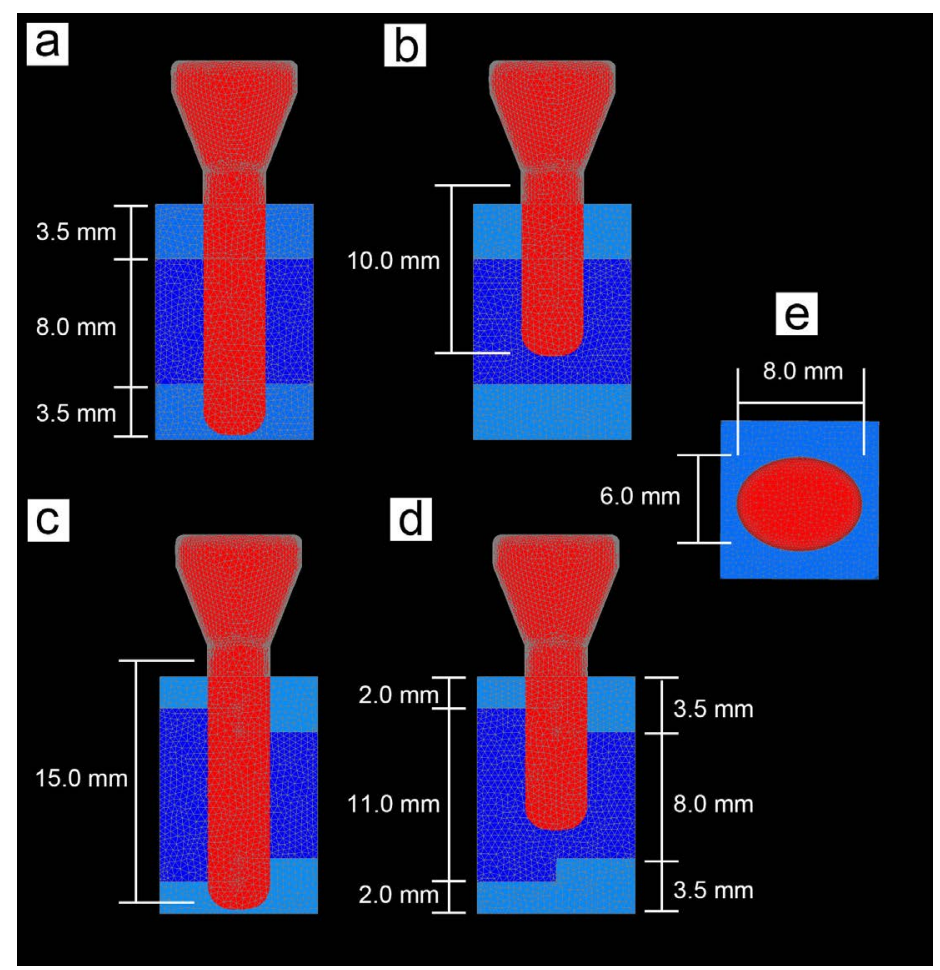

Figure 2. (a)-(d) Mesiodistal cross sections of the 4 simulated models with a prosthesis showing different bone models and implant lengths (a) A fibular model with bicortical fixation and a 15-mm implant (FMB). (b) A fibular model with monocortical fixation and a 10-mm implant (FMM). (c) A transplantation model with bicortical fixation and a $15-\mathrm{mm}$ implant (TMB). (d) A transplantation model with monocortical fixation and a $10-\mathrm{mm}$ implant (TMM). (e) View of the occlusal surface of the prosthesis.

cylinder-type implants, both with a diameter of $4.0 \mathrm{~mm}$ and lengths of 10 and $15 \mathrm{~mm}$, were modeled. The occlusal surface of the prosthesis was elliptical with a vertical diameter of 6.0 and a horizontal diameter of $8.0 \mathrm{~mm}$ (Figure 2(e)). The prosthesis was transitioned from the occlusal surface to the implant collar.

The implant was placed in the center of the bone model, which was at the border between mandible and fibula in TM. The implant length was $10 \mathrm{~mm}$ in monocortical models and $15 \mathrm{~mm}$ in the bicortical models. Four models 
were constructed by altering the cortical model and implant positions.

The finalized computer-designed models were discretized into tetrahedral elements with a rectangular base using the FEA software Mechanical Finder Extended Edition (version 6.2; Research Center of Computational Mechanics, Inc., Tokyo, Japan), resulting in finite elemental meshes arranged in a 3D pattern. The elements were set over a range of $0.2-0.5 \mathrm{~mm}$. Meshes of 373,848 elements and 66,558 nodes, 374,033 elements and 66,536 nodes, 376,612 elements and 67,126 nodes, and 377,393 elements and 67,190 nodes were generated for FM with bicortical fixation (FMB), FM with monocortical fixation (FMM), TM with bicortical fixation (TMB), and TM with monocortical fixation (TMM), respectively.

The models presented characteristics of linear elasticity. The homogeneity principle was also adopted because the materials were assumed as homogenous and isotropic. The interfaces between the cortical bone, cancellous bone, implant, and prosthesis were assumed to be sufficiently bonded, corresponding to good osseointegration. Input data for the implant and prosthesis were obtained from those made using pure titanium, with a Young's modulus of $105.91 \mathrm{GPa}$ and a Poisson ratio of 0.11. The Young's modulus and Poisson ratio for cortical bone are $14.70 \mathrm{GPa}$ and 0.30 , respectively, and those for cancellous boneare $0.49 \mathrm{GPa}$ and 0.30 , respectively [22] [26].

The lower surface of each model was completely constrained. Some studies have reported a force of approximately $200 \mathrm{~N}$ applied to a molar [27] [28]. In this study, we selected a force of $100 \mathrm{~N}$ in order to avoid overstress to the model. The size of force was limited to a diameter of $2.0 \mathrm{~mm}$ and loading positions were set as center, mesial, and distal on the upper surface of the prosthesis (Figure 3).

Von Mises equivalent stress values at the mesial and distal sides of the cortical bone near the implant border were measured at 4 points on the upper surface to a depth of $2 \mathrm{~mm}$ at $0.5-\mathrm{mm}$ increments at the middle line between buccal and lingual side, respectively. The bone near the implant apex was also measured at 4 points from the implant apex, at every $0.5 \mathrm{~mm}$ (Figure 4). There was a maximum number of 16 points in this model.

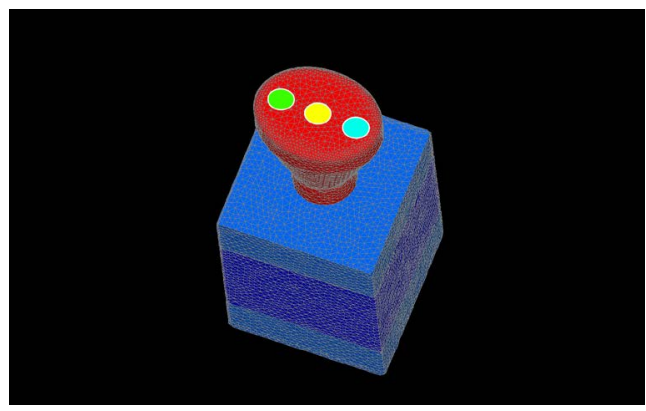

Figure 3. The force was set at $2 \mathrm{~mm}$ and loading positions set at the center (yellow), mesial (green), and distal (blue) points on the upper surface of the prosthesis, respectively.

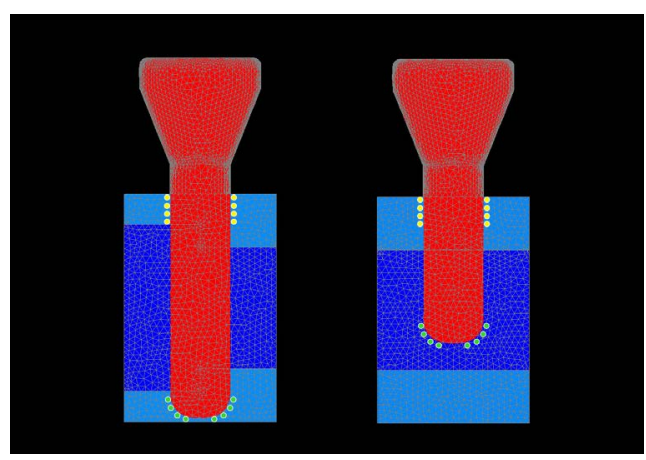

Figure 4. Points for measurement of von Mises equivalent stress. The implant collar is indicated in yellow and the implant apex in green. (left) Fibular model. (right) Transplantation model. 
All values are expressed as means \pm standard deviation. Statistical analysis was performed by 1 -way analysis of variance and Tukey's honestly significant difference test $(p<0.05)$ or the Games-Howell test $(p<0.05)$, where necessary. SPSS software for Windows was used for the analysis (PASW Statistics 18.0; SPSS Inc., Tokyo, Japan).

\section{Results}

The mean von Mises equivalent stress values of the mesial and distal sides with three loading situations in 4 models are described (Table 1; Figures 5-8).
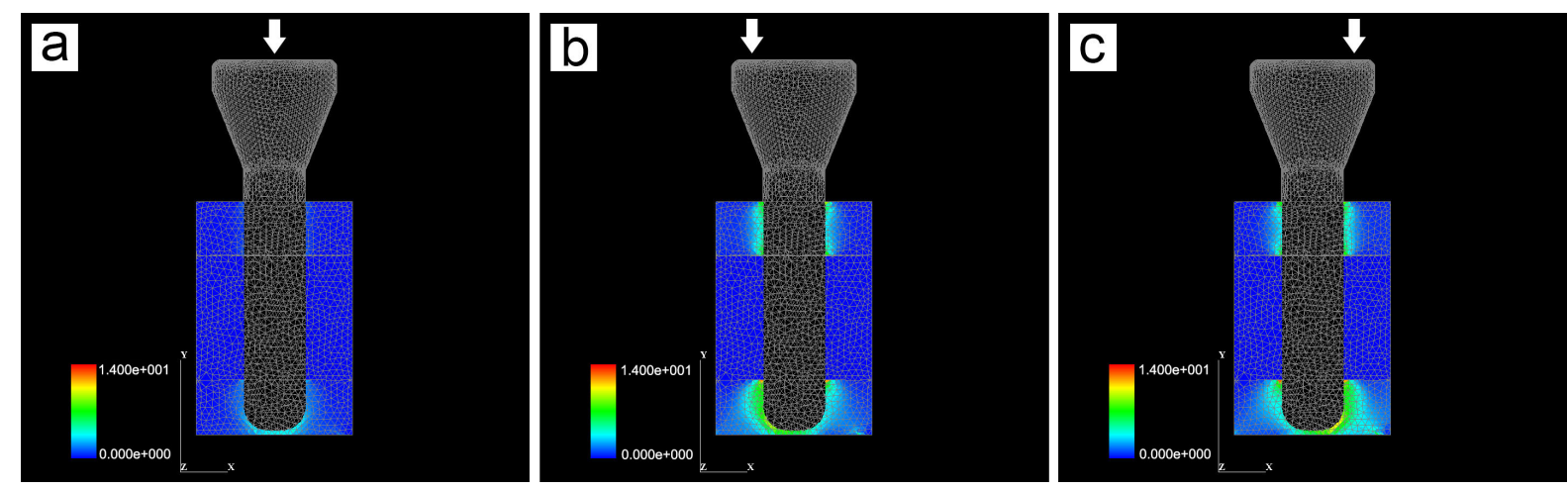

Figure 5. In FMB, the mesiodistal cross sections of von Mises equivalent stress contour patterns with a color bar ranging from $0.000 \mathrm{e}+000$ to $1.4000 \mathrm{e}+001 \mathrm{MPa}\left(\mathrm{N} / \mathrm{mm}^{2}\right.$ ). (a) Center loading. (b) Mesial loading. (c) Distal loading.
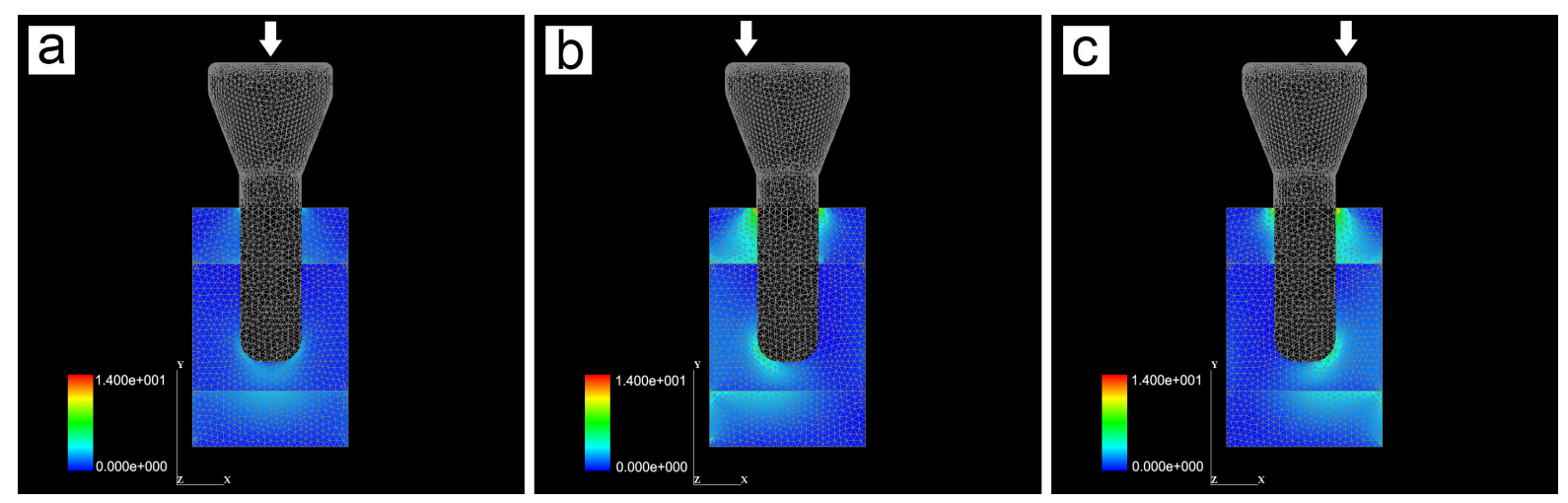

Figure 6. In FMM, the mesiodistal cross-sections of von Mises equivalent stress contour patterns with a color bar ranging from $0.000 \mathrm{e}+000$ to $1.4000 \mathrm{e}+001 \mathrm{MPa}\left(\mathrm{N} / \mathrm{mm}^{2}\right)$. (a) Center loading. (b) Mesial loading. (c) Distal loading.
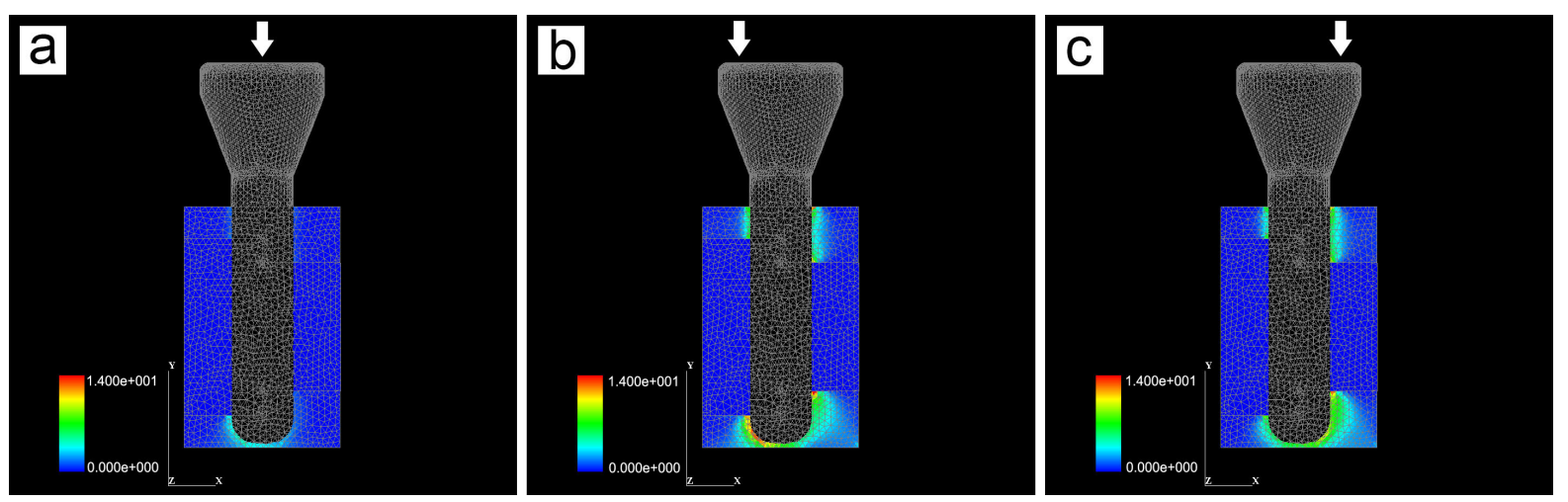

Figure 7. In TMB, the mesiodistal cross-sections of von Mises equivalent stress contour patterns with a color bar ranging from $0.000 \mathrm{e}+000$ to $1.4000 \mathrm{e}+001 \mathrm{MPa}\left(\mathrm{N} / \mathrm{mm}^{2}\right)$. (a) Center loading. (b) Mesial loading. (c) Distal loading. 

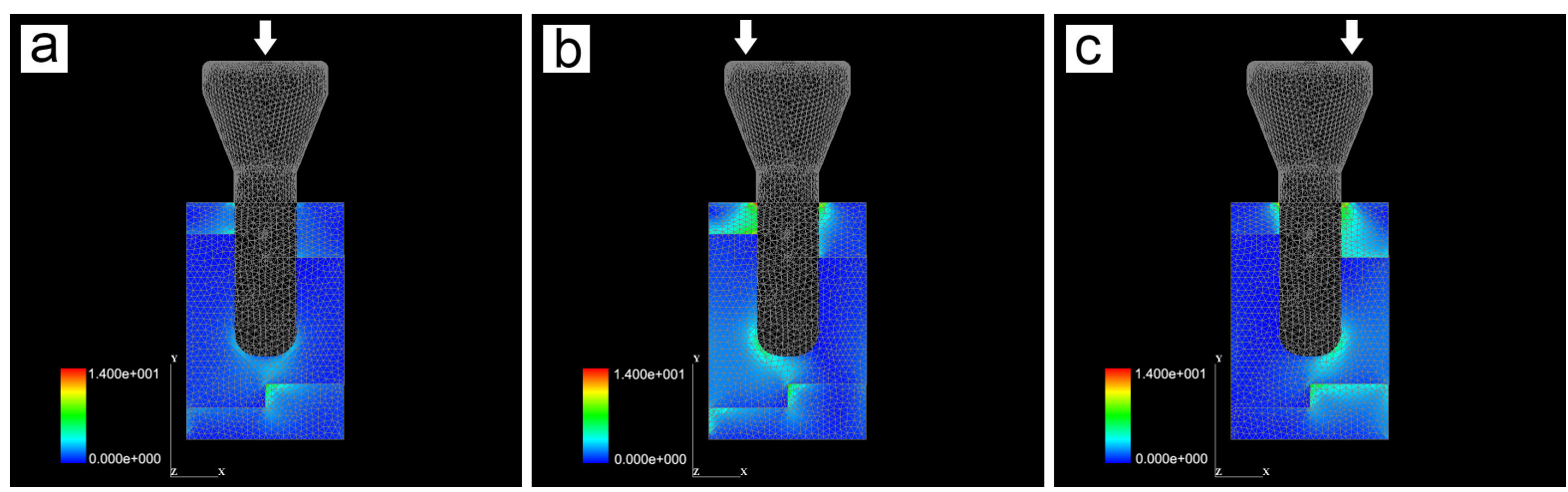

Figures 8. In TMM, the mesiodistal cross sections of von Mises equivalent stress contour patterns with a color bar ranging from $0.000 \mathrm{e}+000$ to $1.4000 \mathrm{e}+001 \mathrm{MPa}\left(\mathrm{N} / \mathrm{mm}^{2}\right)$. (a) Center loading. (b) Mesial loading. (c) Distal loading.

Table 1. Mean von Mises equivalent stress values for all situations $(n=4)$.

\begin{tabular}{|c|c|c|c|c|c|c|}
\hline \multirow{3}{*}{$\begin{array}{l}\text { Bone } \\
\text { model }\end{array}$} & \multirow{3}{*}{$\begin{array}{l}\text { Implant } \\
\text { position }\end{array}$} & \multirow{3}{*}{ Bone } & \multirow{3}{*}{ Side } & \multicolumn{3}{|c|}{ The mean value $\pm \mathrm{SD}\left[\mathrm{MPa}\left(\mathrm{N} / \mathrm{mm}^{2}\right)\right]$} \\
\hline & & & & \multicolumn{3}{|c|}{ Loading position } \\
\hline & & & & Center & Mesial & Distal \\
\hline \multirow{8}{*}{ Fibula } & \multirow{4}{*}{ Bicortical } & \multirow{2}{*}{ Collar } & Mesial & $0.78 \pm 0.10$ & $5.01 \pm 0.88$ & $4.44 \pm 1.85$ \\
\hline & & & Distal & $0.86 \pm 0.12$ & $4.79 \pm 1.82$ & $5.25 \pm 0.84$ \\
\hline & & \multirow{2}{*}{ Apex } & Mesial & $3.12 \pm 0.47$ & $8.74 \pm 0.36$ & $4.25 \pm 0.28$ \\
\hline & & & Distal & $3.14 \pm 0.40$ & $4.48 \pm 0.41$ & $9.16 \pm 1.34$ \\
\hline & \multirow{4}{*}{ Monocortical } & \multirow{2}{*}{ Collar } & Mesial & $1.80 \pm 0.47$ & $7.77 \pm 2.56$ & $5.94 \pm 3.13$ \\
\hline & & & Distal & $1.93 \pm 0.62$ & $5.89 \pm 4.67$ & $7.97 \pm 3.06$ \\
\hline & & \multirow{2}{*}{ Apex } & Mesial & $2.12 \pm 0.26$ & $5.01 \pm 1.85$ & $0.77 \pm 0.34$ \\
\hline & & & Distal & $2.21 \pm 0.49$ & $0.66 \pm 0.37$ & $5.06 \pm 1.91$ \\
\hline \multirow{8}{*}{ Transplantation } & \multirow{4}{*}{ Bicortical } & \multirow{2}{*}{ Collar } & Mesial & $0.97 \pm 0.19$ & $6.26 \pm 1.11$ & $4.69 \pm 1.31$ \\
\hline & & & Distal & $0.84 \pm 0.22$ & $4.87 \pm 1.08$ & $6.76 \pm 1.84$ \\
\hline & & \multirow{2}{*}{ Apex } & Mesial & $4.13 \pm 0.43$ & $11.67 \pm 2.10$ & $6.02 \pm 0.55$ \\
\hline & & & Distal & $2.15 \pm 0.22$ & $5.81 \pm 0.62$ & $9.22 \pm 0.48$ \\
\hline & \multirow{4}{*}{ Monocortical } & \multirow{2}{*}{ Collar } & Mesial & $1.81 \pm 0.47$ & $7.43 \pm 2.00$ & $4.14 \pm 1.48$ \\
\hline & & & Distal & $1.74 \pm 0.53$ & $5.10 \pm 1.87$ & $7.74 \pm 3.71$ \\
\hline & & \multirow{2}{*}{ Apex } & Mesial & $2.12 \pm 0.48$ & $4.33 \pm 1.04$ & $0.93 \pm 0.69$ \\
\hline & & & Distal & $2.33 \pm 0.25$ & $0.60 \pm 0.42$ & $4.32 \pm 0.84$ \\
\hline
\end{tabular}

\subsection{Loading Position}

Differences among loading positions were investigated by comparisons of mean values of the 16 points located on the bone near the collar and apex of the implant (Table 2). In all models, the stress values with center loading (Figure 5(a), Figure 6(a), Figure 7(a) and Figure 8(a)) were significantly lower than those with mesial (Figure 5(b), Figure 6(b), Figure 7(b) and Figure 8(b)) and distal loading (Figure 5(c), Figure 6(c), Figure $7(c)$ and Figure 8(c)).

\subsection{Insert Position}

Differences among insert positions were investigated by comparisons of mean values at 8 points, which were 
located along the bone near the implant collar (Table 3). The values of bone near the implant apex were excluded because they were outliers in both bicortical and monocortical models. In center loading, the stress values of FMB (Figure 5(a)) were significantly lower than those of FMM (Figure 6(a)); similarly, stress values of TMB (Figure 7(a)) were significant lower than those of TMM (Figure 8(a)).

\subsection{Bone Model}

Differences between the FM and TM under the same conditions were investigated by comparison of mean values of the 16 points on the models, which were located around the bone near the collar and apex of the implant. As shown in Table 4, there were no significant differences among all experimental conditions (Table 4).

Table 2. Mean von Mises equivalent stress values for bone near the collar and apex of the implant $(\mathrm{n}=16) .{ }^{* 1}$ : There were significant differences between center loading and mesial loading, and center loading and distal loading. ${ }^{*}$ : There were significant differences between center loading and distal loading.

\begin{tabular}{|c|c|c|c|c|}
\hline \multirow{3}{*}{$\begin{array}{l}\text { Bone } \\
\text { model }\end{array}$} & \multirow{3}{*}{$\begin{array}{l}\text { Implant } \\
\text { position }\end{array}$} & \multicolumn{3}{|c|}{ The mean value $\pm \mathrm{SD}\left[\mathrm{MPa}\left(\mathrm{N} / \mathrm{mm}^{2}\right)\right]$} \\
\hline & & \multicolumn{3}{|c|}{ Loading position } \\
\hline & & Center $^{* 1,2}$ & Mesial $^{* 1}$ & Distal $^{* 2}$ \\
\hline \multirow{2}{*}{ Fibula } & Bicortical & $1.98 \pm 1.22$ & $5.76 \pm 2.02$ & $5.77 \pm 2.33$ \\
\hline & Monocortical & $2.02 \pm 0.46$ & $4.83 \pm 3.69$ & $4.93 \pm 3.46$ \\
\hline \multirow{2}{*}{ Transplantation } & Bicortical & $2.02 \pm 1.38$ & $7.15 \pm 2.99$ & $6.67 \pm 2.00$ \\
\hline & Monocortical & $2.00 \pm 0.47$ & $4.36 \pm 2.86$ & $4.28 \pm 3.10$ \\
\hline
\end{tabular}

Table 3. Mean von Mises equivalent stress values for the bone near the implant collar $(n=8){ }^{* 1}$ : There was a significant difference between FMB and FMM. ${ }^{* 2}$ : There was a significant difference between TMB and TMM.

\begin{tabular}{ccccc}
\hline & & \multicolumn{3}{c}{ The mean value \pm SD $\left[\mathrm{MPa}\left(\mathrm{N} / \mathrm{mm}^{2}\right)\right]$} \\
\cline { 3 - 4 } $\begin{array}{c}\text { Bone } \\
\text { model }\end{array}$ & Implant & \multicolumn{3}{c}{ Loading position } \\
\cline { 3 - 4 } & & Center & Mesial & Distal \\
\cline { 3 - 4 } Fibula & Bicortical & $0.82 \pm 0.11^{* 1}$ & $4.90 \pm 1.33$ & $4.84 \pm 1.40$ \\
& Monocortical & $1.87 \pm 0.51^{* 1}$ & $6.83 \pm 3.63$ & $6.95 \pm 3.06$ \\
Transplantation & Bicortical & $0.90 \pm 0.20^{* 2}$ & $5.56 \pm 1.26$ & $5.73 \pm 1.84$ \\
& Monocortical & $1.77 \pm 0.46^{* 2}$ & $6.26 \pm 2.18$ & $5.94 \pm 3.25$ \\
\hline
\end{tabular}

Table 4. Mean von Mises equivalent stress values for the bone near the implant collar and apex $(n=16)$.

\begin{tabular}{|c|c|c|c|c|}
\hline \multirow{3}{*}{$\begin{array}{l}\text { Bone } \\
\text { model }\end{array}$} & \multirow{3}{*}{$\begin{array}{l}\text { Implant } \\
\text { position }\end{array}$} & \multicolumn{3}{|c|}{ The mean value $\pm \mathrm{SD}\left[\mathrm{MPa}\left(\mathrm{N} / \mathrm{mm}^{2}\right)\right]$} \\
\hline & & \multicolumn{3}{|c|}{ Loading position } \\
\hline & & Center & Mesial & Distal \\
\hline Fibula & \multirow{2}{*}{ Bicortical } & $1.98 \pm 1.22$ & $5.76 \pm 2.02$ & $5.77 \pm 2.33$ \\
\hline Transplantation & & $2.02 \pm 1.38$ & $7.15 \pm 2.99$ & $6.67 \pm 2.00$ \\
\hline Fibula & \multirow{2}{*}{ Monocortical } & $2.02 \pm 0.46$ & $4.83 \pm 3.69$ & $4.93 \pm 3.46$ \\
\hline Transplantation & & $2.00 \pm 0.47$ & $4.36 \pm 2.86$ & $4.28 \pm 3.10$ \\
\hline
\end{tabular}

\section{Discussion}

The ideal condition for an implant is a sufficient cortical bone support against the occlusal force [29]. Some studies [30] [31] have reported good long-term prognosis of implants and others [12] [13] [18] [19] [20] [25] have arrived at the same conclusion with fibular grafts. However, there are relatively few reports on the use of im- 
plants with fibular grafts; therefore, the efficacy of this treatment option remains controversial.

In some studies, FEA was performed at an acute angle of 45 degrees [19] [32] [33] to duplicate the angle of occlusion. However, reconstruction varies among cases due individual differences. In the present study, the loading angle was set verticality to the upper surface of the prosthesis to exclude phenomena caused by morphological differences among patients. In addition, the following three loading positions were set: center, mesial and distal (Figure 3). A single-tooth prosthesis was assumed for all models. However, different loading positions were tested to identify the mechanisms responsible while using a cantilevered prosthesis. Our results showed that stress values were significantly lower with center loading than with mesial and distal loading (Table 2). Yokoyama et al. [22] reported that bone stress was increased by moving the loading position away from the center of the implant site, which was in accordance with our results, showing that bone stress was lowest at the center loading position under similar conditions in FM and TM.

The use of cortical bone is important to achieve implant stability. Generally, monocortical fixation is used in which the penetration of the cortical bone occurs only near the implant collar. Bicortical fixation involves the use of 2 layers of cortical bone near the collar and apex of the implant. Some studies reported a decrease in bone stress by bicortical fixation [19] [20] [31]. Even by FEA, Holberg et al. [34] reported that stress was significantly lower in bicortical fixation than in monocortical fixation. Moreover, other studies [28] [35] reported a decrease in stress levels at the cortical bone near the upper base by the deep positioning of implant and using a longer implant. In this report, the center loading position was associated with significantly lower stress in the cortical bone near the implant collar in the bicortical model than in the monocortical model (Table 3); however, there was no significant difference between the mesial and distal loading positions. Another study reported that stress during off-axis loading of the implant was concentrated in the cortical bone near the implant collar [22]. Therefore, the mesial and distal loading positions did not offer the same benefits for decreasing stress levels in the cortical bone near the implant apex in the bicortical model as well.

Huang et al. [36] and Haibin et al. [37] reported that bone stress levels were increased when the cortical bone is thin. In implant treatment, loading stress was concentrated on the thin cortical bone, which resulted in implant loss [38]. The main difference between the fibula and mandible is the thickness of cortical bone $(2.0$ and $3.5 \mathrm{~mm}$, respectively) [23]-[25] Chiapasco et al. [39] and Kramer et al. [40] reported that FEA did not reveal significant differences in stress values between the mandible and fibular graft. In this study, FM and TM were modeled under these same conditions. The thickness of the mesial cortical bone of TM was $2.0 \mathrm{~mm}$ and that of the distal cortical bone was $3.5 \mathrm{~mm}$ (Figure 2). However, this difference did not cause a significant difference in bone stress values at these 2 positions (Table 4). In addition, our results are in agreement with those of Huang et al. [36], who reported that a cortical bone thickness of $2.0 \mathrm{~mm}$ was sufficient to stabilize the implant.

QOL of patients receiving reconstructive treatment can improve with the use of implants compared with that of patients receiving general care [11]. However, no study has investigated the benefits of implants placed at the border between host bone and bone grafts. Hidalgo et al. [41] reported that the border between the mandible and transplanted fibular graft was stable. In our clinic, we experienced a case that required tumor resection in which a fibular graft was used for mandibular reconstruction. In this case, the implant was placed at a distance of $2 \mathrm{~mm}$ from the tooth on the border between the mandible and fibula using bicortical fixation (Figure 9). The reconstruction has lasted for $>13$ years without any problem. In this study, we simulated a simple implant model and employed FEA to evaluate bone stress. Our results showed that there were not mechanical problems when the implant was placed on the border between the mandible and the fibular graft.

However, there were some limitations associated with the present FEA. Our model did not take into account individual differences, including those in occlusal force, occlusal angle, occlusal muscle strength, bone quality, and bone thickness. Therefore, further studies are necessary to identify appropriate models for FEA.

\section{Conclusion}

In this study, we constructed a 3D model using FEA for assessing bone stress when an implant was placed at the border between the mandible and fibular graft to investigate bone stress. Our results showed that bone stress was significantly increased by use of a loading position away from the center of the implant. Center loading in a bicortical anchored model was associated with a significant decrease in bone stress. There were no significant differences between FM and TM. The results of this study sufficiently indicated that an implant should not be placed at a more distal position in a mesial cantilever prosthesis in an attempt to avoid a position on the border between 

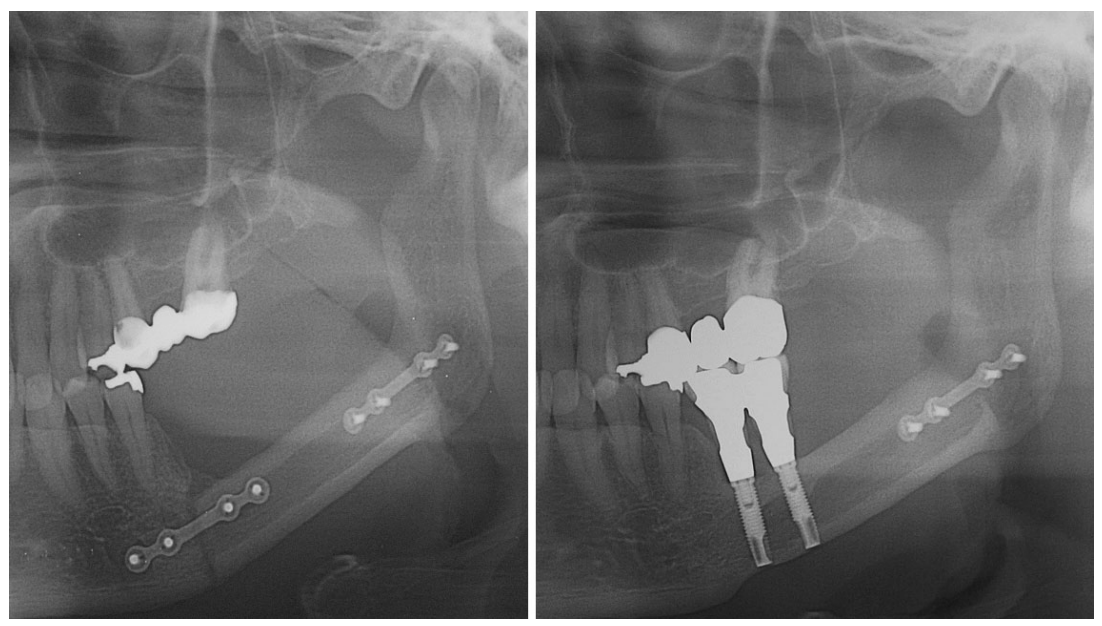

Figure 9. A case of tumor resection and reconstruction surgery (left) 13 years after placement of implants.

the host bone and the graft.

\section{References}

[1] Ormianer, Z., Palti, A., Demiralp, B., Heller, G., Lewinstein, I. and Khayat, P.G. (2012) Implant-Supported First Molar Restorations: Correlation of Finite Element Analysis with Clinical Outcomes. The International Journal of Oral \& Maxillofacial Implants, 27, e1-e12.

[2] Fazi, G., Tellini, S., Vangi, D. and Branchi, R. (2011) Three-Dimensional Finite Element Analysis of Different Implant Configurations for a Mandibular Fixed Prosthesis. The International Journal of Oral \& Maxillofacial Implants, 26, 752-759.

[3] Lan, T.H., Pan, C.Y., Lee, H.E., Huang, H.L. and Wang, C.H. (2010) Bone Stress Analysis of Various Angulations of Mesiodistal Implants with Splinted Crowns in the Posterior Mandible: A Three-Dimensional Finite Element Study. The International Journal of Oral \& Maxillofacial Implants, 25, 763-770.

[4] Çaglar, A., Bal, B.T., Karakoca, S., Aydın, C., Yılmaz, H. and Sarısoy, S. (2011) Three-Dimensional Finite Element Analysis of Titanium and Yttrium-Stabilized Zirconium Dioxide Abutments and Implants. The International Journal of Oral \& Maxillofacial Implants, 26, 961-969.

[5] Pierrisnard, L., Hure, G., Barquins, M. and Chappard, D. (2002) Two Dental Implants Designed for Immediate Loading: A Finite Element Analysis. The International Journal of Oral \& Maxillofacial Implants, 17, 353-362.

[6] Pessoa, R.S., Coelho, P.G., Muraru, L., Marcantonio, E., Vaz, L.G., Vander Sloten, J., et al. (2011) Influence of Implant Design on the Biomechanical Environment of Immediately Placed Implants: Computed Tomography-Based Nonlinear Three-Dimensional Finite Element Analysis. The International Journal of Oral \& Maxillofacial Implants, 26, 1279-1287.

[7] Winter, W., Möhrle, S., Holst, S. and Karl, M. (2010) Parameters of Implant Stability Measurements Based on Resonance Frequency and Damping Capacity: A Comparative Finite Element Analysis. The International Journal of Oral \& Maxillofacial Implants, 25, 532-539.

[8] Hong, H.R., Pae, A., Kim, Y., Paek, J., Kim, H.S. and Kwon, K.R. (2012) Effect of Implant Position, Angulation, and Attachment Height on Peri-Implant Bone Stress Associated with Mandibular Two-Implant Overdentures: A Finite Element Analysis. The International Journal of Oral \& Maxillofacial Implants, 27, e69-e76.

[9] Huang, H.L., Fuh, L.J., Ko, C.C., Hsu, J.T. and Chen, C.C. (2009) Biomechanical Effects of a Maxillary Implant in the Augmented Sinus: A Three-Dimensional Finite Element Analysis. The International Journal of Oral \& Maxillofacial Implants, 24, 455-462.

[10] Choi, K.S., Park, S.H., Lee, J.H., Jeon, Y.C., Yun, M.J. and Jeong, C.M. (2012) Stress Distribution on Scalloped Implants with Different Microthread and Connection Configurations Using Three-Dimensional Finite Element Analysis. The International Journal of Oral \& Maxillofacial Implants, 27, e29-e38.

[11] Fang, Q.G., Shi, S., Zhang, X., Li, Z.N., Liu, F.Y. and Sun, C.F. (2013) Assessment of the Quality of Life of Patients with Oral Cancer after Pectoralis Major Myocutaneous Flap Reconstruction with a Focus on Speech. Journal of Oral and Maxillofacial Surgery, 71, e1-e5. http://dx.doi.org/10.1016/j.joms.2013.07.011 
[12] Chiapasco, M., Romeo, E., Coggiola, A. and Brusati, R. (2011) Long-Term Outcome of Dental Implants Placed in Revascularized Fibula Free Flaps Used for the Reconstruction of Maxillo-Mandibular Defects Due to Extreme Atrophy. Clinical Oral Implants Research, 22, 83-91. http://dx.doi.org/10.1111/j.1600-0501.2010.01999.x

[13] Anne-Gaëlle, B., Samuel, S., Julie, B., Renaud, L. and Pierre, B. (2011) Dental Implant Placement after Mandibular Reconstruction by Microvascular Free Fibula Flap: Current Knowledge and Remaining Questions. Oral Oncology, 47, 1099-1104. http://dx.doi.org/10.1016/j.oraloncology.2011.07.016

[14] Kurz, L.T., Garfin, S.R. and Booth, R.E. (1989) Harvesting Autogenous Iliac Bone Grafts. A Review of Complications and Techniques. Spine, 14, 1324-1331. http://dx.doi.org/10.1097/00007632-198912000-00009

[15] Boyd, J.B., Rosen, I., Rotstein, L., Freeman, J., Gullane, P., Manktelow, R., et al. (1990) The Iliac Crest and the Radial Forearm Flap in Vascularized Oromandibular Reconstruction. The American Journal of Surgery, 159, 301-308. http://dx.doi.org/10.1016/S0002-9610(05)81223-1

[16] Hidalgo, D.A. (1991) Aesthetic Improvements in Free-Flap Mandible Reconstruction. Plastic and Reconstructive Surgery, 88, 574-587. http://dx.doi.org/10.1097/00006534-199110000-00003

[17] Swartz, W.M., Banis, J.C., Newton, E.D., Ramasastry, S.S., Jones, N.F. and Acland, R. (1986) The Osteocutaneous Scapular Flap for Mandibular and Maxillary Reconstruction. Plastic and Reconstructive Surgery, 77, 530-545. http://dx.doi.org/10.1097/00006534-198604000-00003

[18] Reychler, H. and Iriarte Ortabe, J. (1994) Mandibular Reconstruction with the Free Fibula Osteocutaneous Flap. International Journal of Oral and Maxillofacial Surgery, 23, 209-213. http://dx.doi.org/10.1016/S0901-5027(05)80372-8

[19] Wu, J.C., Chen, C.S., Yip, S.W. and Hsu, M.L. (2012) Stress Distribution and Micromotion Analyses of Immediately Loaded Implants of Varying Lengths in the Mandible and Fibular Bone Grafts: A Three-Dimensional Finite Element Analysis. The International Journal of Oral \& Maxillofacial Implants, 27, e77-e84.

[20] Hakim, S.G., Jeske, G., Jacobsen, H.C. and Sieg, P. (2012) The Eligibility of the Free Fibula Graft for Masticatory Rehabilitation Using Monocortical Implants Insertion-A Morphologic and Biomechanical Study. Clinical Oral Investigations, 16, 673-678. http://dx.doi.org/10.1007/s00784-011-0582-3

[21] Kourkouta, S., Dedi, K.D., Paquette, D.W. and Mol, A. (2009) Interproximal Tissue Dimensions in Relation to Adjacent Implants in the Anterior Maxilla: Clinical Observations and Patient Esthetic Evaluation. Clinical Oral Implants Research, 20, 1375-1385. http://dx.doi.org/10.1111/j.1600-0501.2009.01761.x

[22] Yokoyama, S., Wakabayashi, N., Shiota, M. and Ohyama, T. (2004) The Influence of Implant Location and Length on Stress Distribution for Three-Unit Implant-Supported Posterior Cantilever Fixed Partial Dentures. Journal of Prosthetic Dentistry, 91, 234-240. http://dx.doi.org/10.1016/j.prosdent.2003.12.017

[23] Vinicius de Oliveira, M., de Moraes, P.H., Olate, S., Alonso, M.B., Watanabe, P.C., Haiter-Neto, F., et al. (2012) Morphometric Study of Mandibular Ramus Related to Sagittal Ramus Split Osteotomy and Osteosynthesis. Journal of Craniofacial Surgery, 23, 1484-1487. http://dx.doi.org/10.1097/SCS.0b013e318256664d

[24] Roberts, M., Yuan, J., Graham, J., Jacobs, R. and Devlin, H. (2011) Changes in Mandibular Cortical Width Measurements with Age in Men and Women. Osteoporosis International, 22, 1915-1925. http://dx.doi.org/10.1007/s00198-010-1410-3

[25] Park, Y.S. and Kwon, H.B. (2013) Three-Dimensional Finite Element Analysis of Implant-Supported Crown in Fibula Bone Model. Journal of Advanced Prosthodontics, 5, 326-332. http://dx.doi.org/10.4047/jap.2013.5.3.326

[26] Farah, J.W., Craig, R.G. and Meroueh, K.A. (1989) Finite Element Analysis of Three- and Four-Unit Bridges. Journal of Oral Rehabilitation, 16, 603-611. http://dx.doi.org/10.1111/j.1365-2842.1989.tb01384.x

[27] Mericske-Stern, R., Assal, P., Mericske, E. and Bürgin, W. (1995) Occlusal Force and Oral Tactile Sensibility Measured in Partially Edentulous Patients with ITI Implants. The International Journal of Oral \& Maxillofacial Implants, 10, 345-353.

[28] Guan, H., van Staden, R., Loo, Y.C., Johnson, N., Ivanovski, S. and Meredith, N. (2009) Influence of Bone and Dental Implant Parameters on Stress Distribution in the Mandible: A Finite Element Study. The International Journal of Oral \& Maxillofacial Implants, 24, 866-876.

[29] Brånemark, P.I., Hansson, B.O., Adell, R., Breine, U., Lindström, J., Hallén, O., et al. (1977) Osseointegrated Implants in the Treatment of the Edentulous Jaw. Experience from a 10-Year Period. Scandinavian Journal of Plastic and Reconstructive Surgery. Supplementum, 16, 1-132.

[30] De Bruyn, H., Bouvry, P., Collaert, B., De Clercq, C., Persson, G.R. and Cosyn, J. (2013) Long-Term Clinical, Microbiological, and Radiographic Outcomes of Brånemark ${ }^{\mathrm{TM}}$ Implants Installed in Augmented Maxillary Bone for Fixed Full-Arch Rehabilitation. Clinical Implant Dentistry and Related Research, 15, 73-82. http://dx.doi.org/10.1111/j.1708-8208.2011.00359.x

[31] Ivanoff, C.J., Sennerby, L. and Lekholm, U. (1996) Influence of Mono- and Bicortical Anchorage on the Integration of Titanium Implants. A Study in the Rabbit Tibia. International Journal of Oral and Maxillofacial Surgery, 25, 229-235. 
http://dx.doi.org/10.1016/S0901-5027(96)80036-1

[32] Kong, L., Sun, Y., Hu, K., Liu, Y., Li, D., Qiu, Z., et al. (2008) Selections of the Cylinder Implant Neck Taper and Implant End Fillet for Optimal Biomechanical Properties: A Three-Dimensional Finite Element Analysis. Journal of Biomechanics, 41, 1124-1130. http://dx.doi.org/10.1016/i.jbiomech.2007.12.013

[33] Lin, C.L., Wang, J.C., Ramp, L.C. and Liu, P.R. (2008) Biomechanical Response of Implant Systems Placed in the Maxillary Posterior Region under Various Conditions of Angulation, Bone Density, and Loading. The International Journal of Oral \& Maxillofacial Implants, 23, 57-64.

[34] Holberg, C., Winterhalder, P., Rudzki-Janson, I. and Wichelhaus, A. (2013) Finite Element Analysis of Mono- and Bicortical Mini-Implant Stability. The European Journal of Orthodontics, Published Online. http://dx.doi.org/10.1093/ejo/cjt023

[35] Qian, L., Todo, M., Matsushita, Y. and Koyano, K. (2009) Effects of Implant Diameter, Insertion Depth, and Loading Angle on Stress/Strain Fields in Implant/Jawbone Systems: Finite Element Analysis. The International Journal of Oral \& Maxillofacial Implants, 24, 877-886.

[36] Huang, H.L., Chang, Y.Y., Lin, D.J., Li, Y.F., Chen, K.T. and Hsu, J.T. (2011) Initial Stability and Bone Strain Evaluation of the Immediately Loaded Dental Implant: An in Vitro Model Study. Clinical Oral Implants Research, 22, 691698. http://dx.doi.org/10.1111/j.1600-0501.2010.01983.x

[37] Xia, H., Wang, M., Ma, L., Zhou, Y., Li, Z. and Wang, Y. (2013) The Effect of Platform Switching on Stress in PeriImplant Bone in a Condition of Marginal Bone Resorption: A Three-Dimensional Finite Element Analysis. The International Journal of Oral \& Maxillofacial Implants, 28, e122-e127. http://dx.doi.org/10.11607/jomi.2965

[38] Hudieb, M. and Kasugai, S. (2011) Biomechanical Effect of Crestal Bone Osteoplasty before Implant Placement: A Three-Dimensional Finite Element Analysis. International Journal of Oral and Maxillofacial Surgery, 40, $200-206$. http://dx.doi.org/10.1016/j.ijom.2010.10.002

[39] Chiapasco, M., Biglioli, F., Autelitano, L., Romeo, E. and Brusati, R. (2006) Clinical Outcome of Dental Implants Placed in Fibula-Free Flaps Used for the Reconstruction of Maxillo-Mandibular Defects Following Ablation for Tumors or Osteoradionecrosis. Clinical Oral Implants Research, 17, 220-228. http://dx.doi.org/10.1111/j.1600-0501.2005.01212.x

[40] Kramer, F.J., Dempf, R. and Bremer, B. (2005) Efficacy of Dental Implants Placed into Fibula-Free Flaps for Orofacial Reconstruction. Clinical Oral Implants Research, 16, 80-88. http://dx.doi.org/10.1111/j.1600-0501.2004.01040.x

[41] Hidalgo, D.A. (1989) Fibula Free Flap: A New Method of Mandible Reconstruction. Plastic and Reconstructive Surgery, 84, 71-79. http://dx.doi.org/10.1097/00006534-198907000-00014 